Sādhanā Vol. 40, Part 6, September 2015, pp. 1937-1954. (C) Indian Academy of Sciences

\title{
Combustion, performance and emissions characteristics of a newly developed CRDI single cylinder diesel engine
}

\author{
AVINASH KUMAR AGARWAL*, PARAS GUPTA and \\ ATUL DHAR
}

Engine Research Laboratory, Department of Mechanical Engineering, Indian Institute of Technology Kanpur, Kanpur 208016, India

e-mail: akag@iitk.ac.in

MS received 25 November 2013; revised 13 May 2015; accepted 3 August 2015

\begin{abstract}
For improving engine performance, combustion and controlling emissions from compression ignition (CI) engines, common rail direct injection (CRDI) technology offers limitless possibilities by controlling fuel injection parameters such as fuel injection pressure, start of injection (SOI) timing, rate of fuel injection and injection duration. CRDI systems available commercially are quite complex and use a large number of sensors, hardware and analytical circuits, which make them very expensive and unfeasible for cheaper single cylinder engines, typically used in agricultural sector and decentralized power sector.

This paper covers experimental investigations of a simpler version of CRDI system developed for a constant-speed, single-cylinder engine. Modifications in the cylinder head for accommodating solenoid injector, designing injector driver circuit and development of high pressure stage controls were some of the engine modification and development tasks undertaken. SOI timing is an important parameter for improving engine's combustion characteristics. SOI timings were varied between $25^{\circ}$ and $40^{\circ}$ BTDC for investigating engine's performance, emissions and combustion characteristics. Advanced fuel injections showed higher heat release rate (HRR), cylinder pressure and rate of pressure rise (RoPR) because of relatively longer ignition delay experienced. Lowest brake specific fuel consumption (BSFC) was obtained for $34^{\circ}$ CA BTDC SOI. Reduction in engine out emissions except $\mathrm{NO}_{\mathrm{x}}$ was observed for advanced fuel injection timings for this newly developed CRDI system.
\end{abstract}

Keywords. CRDI system; combustion characteristics; start of injection; heat release rate; emissions; combustion duration.

\section{Introduction}

A large segment of modern transportation systems is powered by direct injection diesel engines. This is due to numerous advantages offered by these combustion systems in terms of excellent

${ }^{*}$ For correspondence 
fuel economy and higher power density compared to indirect injection systems as well as spark ignited gasoline engines. Increasing the fuel injection pressures and optimizing the injection strategies are extremely important for further improvements in highly optimized compression ignition (CI) engines. The flexibility to change the injection strategy and multiple injection capabilities are not offered by mechanical fuel injection systems. On the other hand, in electronic fuel injection systems, fuel injection parameters such as injection pressure, fuel injection rate, multiple injections and the start of injection (SOI) are precisely controlled and regulated with great ease by an electronic control unit (ECU) under different engine operating conditions. Electronic fuel injection systems used in modern diesel engines include unit pump system, unit injector system, and CRDI systems. In case of unit injector and unit pump systems, fuel injection pressure depends on the engine speed and they require separate fuel pump assemblies for each cylinder. On the contrary, CRDI system has a high pressure fuel reservoir (common rail), which is supplied fuel by a single high pressure fuel pump. This fuel is then delivered to all the cylinders using high pressure pipes and high pressure solenoid injectors, which are controlled by the ECU individually.

CRDI concept was proposed by Bosch in 1978 for diesel fuel injection for the first time (Eblen \& Stumpp 1978). A stepped piston was provided in each injector, which was able to support the fuel injection pressures ranging from 200 bars to 2,000 bars. This system demonstrated promising advantages in terms of lower combustion noise from the engine as well as lower PM emissions; however, the costs were prohibitively high at that time. A new fuel injection system named 'ECD-U2' was developed (Miyaki et al 1991), which also consisted of an electronic unit injector system and a high pressure common rail. This system could achieve fuel injection pressures up to 1,200 bars. Rinolf et al (1995) further simplified the CRDI system. In their system, fuel injection was controlled by a 2-way solenoid valve rather than a 3-way solenoid valve. Schubiger et al (2001) investigated a heavy-duty diesel engine with a pressure limit up to 1,600 bar. Their system was capable of varying maximum fuel injection pressure up to 1,800 bar. Cheng et al (1999) conducted experiments on a single cylinder engine with fuel injection pressure up to 1,800 bars. Such a high fuel injection pressure provided improved fuel-air mixing and reduced the engine-out emissions. Kong \& Karra (2008) increased the fuel injection pressure further up to 2,000 bar. Such a high pressure significantly reduced the soot emissions further. Shimada et al (1989) carried out research on single cylinder engine to understand the effect of high pressure fuel injections on the exhaust emissions and fuel consumption. They reported that by increasing the fuel injection pressure by modifying fuel pump's injection rate and nozzle area, superior smoke emission characteristics and lower fuel consumption at low and medium engine speeds could be achieved. Kohketsu et al (1994) investigated the effect of different parameters such as fuel injection pressure, injection nozzle hole diameter, swirl ratio, and EGR rate on exhaust emissions, combustion noise and fuel consumption. The results suggested that smaller nozzle hole diameters were effective in reducing smoke and PM emissions. However by optimizing the fuel injection timings, swirl ratio and higher injection pressures, it was also possible to improve the fuel consumption, in addition to lower $\mathrm{NO}_{\mathrm{x}}$ and $\mathrm{PM}$ emissions. Henein et al (2001) also used single cylinder diesel engine to experimentally investigate the effect of fuel injection pressure, EGR rate and swirl ratio on engine performance and emissions. They reported that by increasing the EGR rate (up to 55\%), NOx emissions decreased continuously; however, the smoke increased because of NOx-PM trade-off. Thirouard et al (2009) performed tests on IFP prototype single cylinder engine with very high fuel injection pressures up to 2,500 bars and showed that by combining high fuel injection pressures with high boost and maximum incylinder pressure, very high specific power outputs (85-90 kW/l) and high fuel/air equivalence 
ratios (0.9) could be achieved. Pilot injection shortens the ignition delay of the fuel injected during the main injection; therefore, it reduces the combustion noise. Block et al (2002) discovered formation of homogenous charge of pilot injected fuel quantity with advanced fuel injection timings. Zhang (1999) used a single cylinder high-speed diesel engine equipped with common rail system to investigate the effect of pilot injection on the engine-out emissions and combustion noise, in combination with EGR. They showed that pilot injection leads to a high pressure and temperature environment in the cylinder, which encourages smoother pressure rise and faster ignition of the fuel injected during the main injection pulse. Endres et al (1994) showed that by using the 'pre-injection', there was reduction of $\mathrm{NO}_{\mathrm{x}}$ and particulate emissions, in addition to improvement in combustion noise. Koyanagi et al (1999) investigated the effect of pilot injection in an optical engine using visualization techniques. For a stable pilot injection, Ishiwata et al (1994) developed TICS pilot injection system. To improve $\mathrm{NO}_{\mathrm{x}}-\mathrm{PM}$ trade-off and fuel consumption, Uchida et al (1998) used pilot injection to generate an inert combustion gas, which caused 'EGR effect'. Tow et al (1994) investigated multiple injection strategies using a caterpillar engine with double and triple injections. Riaud \& Lavoisier (2002) carried out research on optimization of multiple injection strategies. In their study, four different injection strategies namely pilot-pilot-main-post injection, retarded pilot-main injection, pilot-pilot-main injection, and advanced pilot-main injection were used. Nakakita et al (1992) concluded that precise control of pilot injection fuel quantity and pilot-main interval are essential for reducing smoke. By using pilot injection, $\mathrm{NO}_{\mathrm{x}}$ reduces for more retarded injection timings because of earlier start of main combustion. Shundoh et al (1992) reported that combination of pilot injection and high fuel injection pressures simultaneously reduces $\mathrm{NO}_{\mathrm{x}}(\sim 35 \%)$ and smoke $(\sim 60-80 \%)$ without adversely affecting fuel economy. They concluded that reduction in ignition delay does not lead to effective improvement at usual injection timings before TDC. However, when the injection timing is considerably retarded or when the original ignition delay is relatively long, shortening of the ignition delay is effective in reducing premixed combustion, therefore the $\mathrm{NO}_{\mathrm{x}}$ emissions reduce. In the CRDI system, post-injection or secondary injection occurs after the main injection, while the combustion process is still on. Using post injection, soot particles are re-ignited and this reduces soot emissions by 20-70\% (Robert Bosch 2006). Tsurushima et al (1999) also reported that post-injection reduces $\mathrm{HC}, \mathrm{CO}$ as well as PM emissions. This was primarily due to the oxidation of unburnt fuel, which remains in the combustion chamber after the completion of main injection. Desantes et al (2007) found that if the post-injection is done close enough to main injection, the end of combustion can take place earlier compared to single injection strategy. Under such conditions, $\mathrm{NO}_{\mathrm{x}}$ emissions increase due to higher temperature levels in the last stage of combustion, and soot formation and specific fuel consumption decrease due to relatively faster combustion in the last phase.

All these however require a large number of sensors at different locations, a powerful microprocessor and a detailed engine calibration exercise to be undertaken, which would make this technology rather expensive and unaffordable for simpler and cheaper engines. There are a very large number of constant speed engines used in decentralized power generation sector, agricultural farm machinery and irrigation purposes, which have not yet reaped the benefits of the new technology because this technology is very expensive. The engines typically used in these niche areas produce $2-10 \mathrm{~kW}$ power, and are cheap, mostly manufactured locally; therefore, this niche area is unfamiliar with the benefits of common rail direct injection (CRDI) engine technology. The objective of this study is therefore to develop a low-cost CRDI system for replacing the existing mechanical FIE system in such constant speed engines with basic CRDI components so that the cost if lower. Performance, emissions and combustion characteristics of this new CRDI 
system are comprehensively investigated for optimizing the fuel injection timings for constant speed engine applications.

\section{Experimental setup}

The test engine used for this investigation is a constant speed, single cylinder, four-stroke, watercooled, direct injection diesel engine (Kirloskar, DM-10), which was coupled to an AC alternator (Kirloskar) for loading it. Detailed specifications of the unmodified test engine are given in table 1 . The schematic of the experimental setup is shown in figure 1.

Fuel injection system of this engine was changed to CRDI fuel injection system. Extensive modifications on the engine cylinder head were carried out for installation of a high pressure solenoid injector and a piezoelectric pressure transducer. The modified CRDI fuel injection system (figure 1) includes a high pressure fuel pump, a common rail, a solenoid fuel injector, a fuel filter, a high pressure fuel-line and a custom-made injection driver (controller) circuit (figure 1(b)). This circuit contains two transformers (12 V/12 amp and 12V/2 amp) and IC 555 for signal generation. The output signal from IC 555 is amplified using transistors (SL100, 2N3055). Fuel injector requires very high current ( $\sim \mathrm{amp})$, which cannot be generated directly by these transistors. Therefore this signal is again amplified using Insulated Gate Bipolar Transistor (IGBT). This amplified signal drives the injector. This newly developed CRDI system was relatively cheaper because it uses cheaper high pressure CRDI pumps, injectors and smaller number of sensors (only TDC sensor, engine speed sensor and exhaust gas sensor), which give their input to the injector driver circuit, which is relatively cheaper compared to an ECU. Using this architecture, the cost of the system drastically reduced for this niche application, where there were very limited operational challenges because the engine always operates at a constant speed of 1,500 rpm.

Engine load was varied by loading the alternator (figure 1). Volumetric fuel flow rate and intake air flow rate were also measured. Raw exhaust gas composition was measured by using exhaust gas emission analyzer (AVL, 444). The exhaust opacity was measured using smoke opacimeter (AVL, 437). This instrument qualitatively determines the particulate present in the engine exhaust. For in-cylinder pressure measurement, a piezoelectric pressure transducer (Kistler Instruments, 6613CQ09-01) was mounted flush with the cylinder head. This pressure transducer operates on a 7-32 V DC power supply and it can measure in-cylinder pressure in the range of 0-75 bar ( 25 bars/volt). Cylinder pressure curve was pegged at 1 bar at the end of suction stroke $\left(-180^{\circ} \mathrm{CA}\right)$. An inductive proximity sensor (Transducers and Allied Products, GLP18APS) was used for TDC detection. A metallic strip was mounted on the camshaft such that it passes in close proximity to that of proximity sensor while piston comes to TDC in compression stroke, once in every cycle. An optical shaft encoder was mounted on the engine

Table 1. Technical specifications of the test engine.

\begin{tabular}{ll}
\hline Engine characteristics & Specifications \\
\hline Make/model & Kirloskar/DM 10 \\
Bore/stroke & $102 / 115 \mathrm{~mm}$ \\
Power output & $7.4 \mathrm{~kW} @ 1,500 \mathrm{rpm}$ \\
Compression ratio & 17.5 \\
Displacement & $975 \mathrm{cc}$ \\
Inlet valve opening & $4.5^{\circ} \mathrm{BTDC}$ \\
Inlet valve closing & $35.5^{\circ} \mathrm{ABDC}$ \\
Exhaust valve opening & $35.5^{\circ} \mathrm{BBDC}$ \\
Exhaust valve closing & $4.5^{\circ} \mathrm{ATDC}$ \\
\hline
\end{tabular}




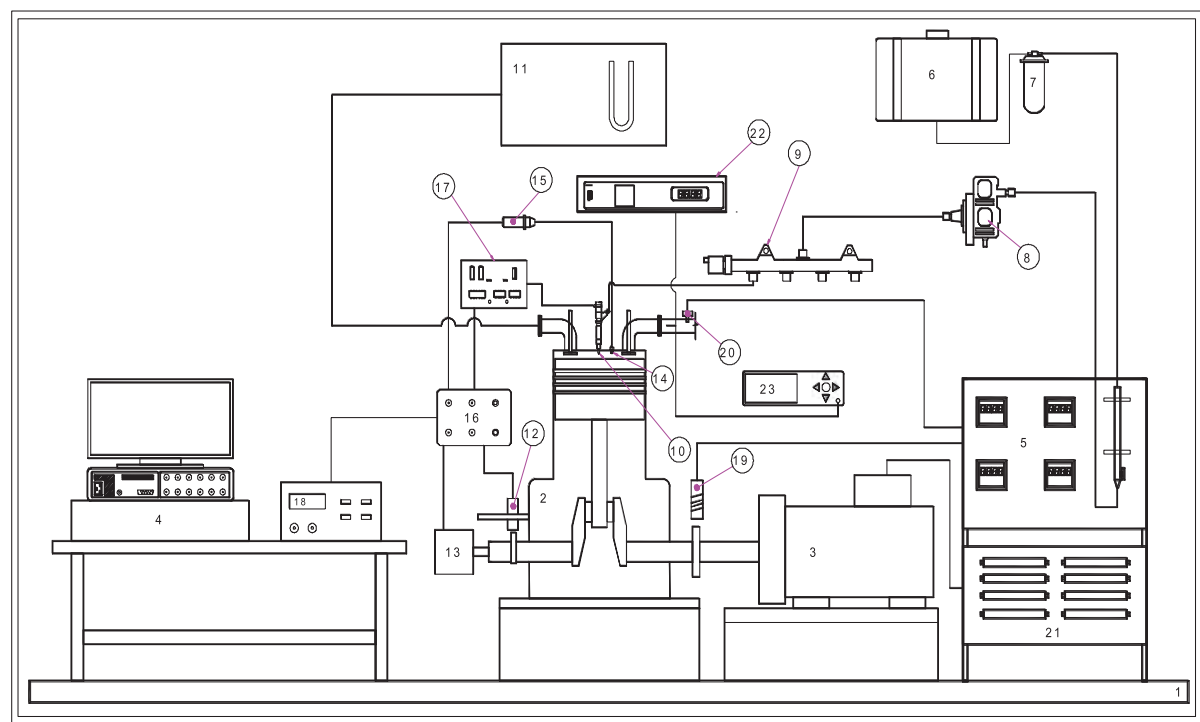

1. Base

2. Engine

3. Alternator

4. Data Acquisition System

5. Control Panel with fuel measurement system

6. Fuel Tank

7. Filter

8. High Pressure Pump

9. Common Rail

10. Solenoid Injector

11. Air Box

12. TDC sensor
13. Shaft encoder

14. Pressure Transducer

15. Charge Amplifier

16. BNC box

17. Injector Driver Circuit

18. Power Supply

19. RPM sensor

20. Temperature Sensor

21. Load Bank

22. Smoke Opacity Meter

23. Gas Analyzer

(a)

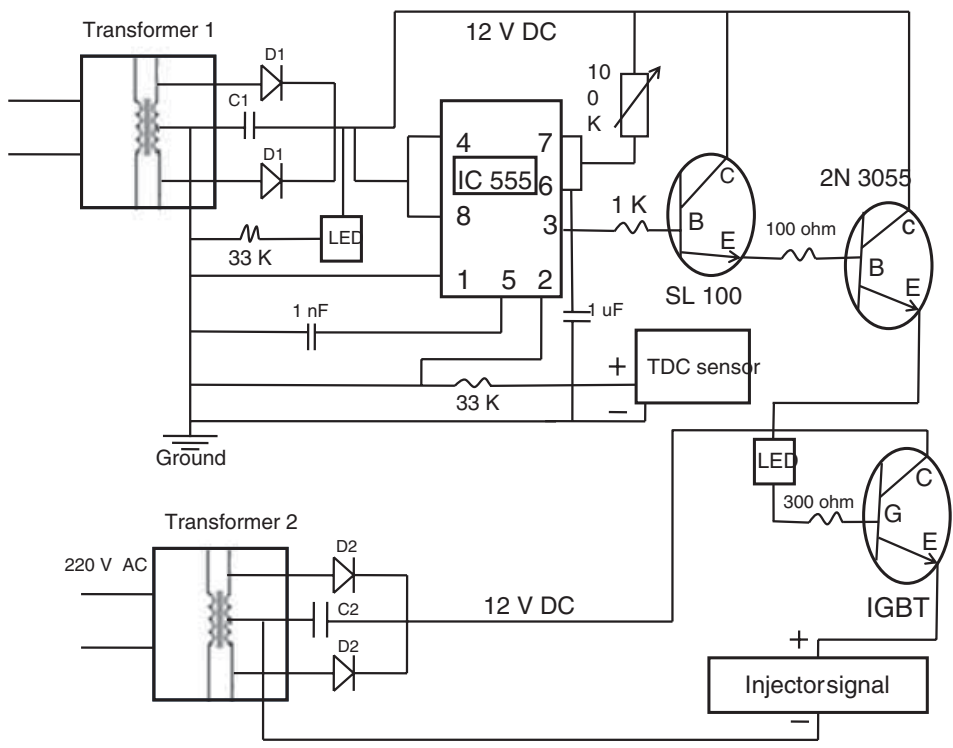

(b)

Figure 1. (a) Schematic of the experimental setup. (b) Circuit diagram of injector driver circuit. 
camshaft, which gives three output signals (A, B and Z). A and B signals were two pulses per crank angle degree with $90^{\circ}$ phase shift. $\mathrm{Z}$ signal was one pulse per revolution of the engine camshaft. A high speed combustion data acquisition system (Hi-Techniques, Synergy) was used, which has eight channels (2MS/s, 16 bit digitizers for each channel), and it provides enough bandwidth for engine combustion diagnostics.

For an unmodified engine with mechanical FIE system, 'start of injection (SOI)' was $30^{\circ}$ BTDC and the nozzle opening pressure was 200-205 bar, as per the manufacturer's recommendations. Keeping this in mind, test engine was operated at a constant speed of 1,500 rpm, with 280 bar fuel injection pressure at different loads in this study. Modified engine's performance and emissions were evaluated for varying SOI of $25^{\circ}, 28^{\circ}, 31^{\circ}, 34^{\circ}, 37^{\circ}$, and $40^{\circ} \mathrm{CA}$ BTDC at different engine loads at 1,500 rpm engine speed. The results are present in the following section.

\section{Results and discussion}

\subsection{Combustion characteristics}

Combustion analysis is extremely important for engine design and analysis because it directly affects the engine performance and emission characteristics, noise, vibrations and durability. For the combustion characterization, in-cylinder combustion data was acquired vis-à-vis engine crank shaft position using high speed data acquisition system for 100 consecutive engine cycles and analysis was performed on an average data set obtained from data of these 100 cycles in order to eliminate the effect of cycle to cycle variations. In-cylinder pressure, pressure rise rate, heat release rate, cumulative heat release rate, mass burn fraction and combustion duration were then calculated and all these parameters were compared for different SOI conditions.

3.1a In-cylinder pressure: The measurement of in-cylinder pressure is an important parameter for understanding engine combustion. The analysis of in-cylinder pressure is used in finding various engine combustion parameters such as heat release rate, cumulative heat release and pressure rise rate. The in-cylinder pressure vs. crank angle for various SOI timings are shown in figure 2 for different engine loads varying from no load to full load.

From these graphs, it is generally observed that advancing the SOI leads to higher in-cylinder pressures at all engine loads. This trend is seen for most of the engine loads consistently except 1.5 and $2.1 \mathrm{~kW}$, where highest in-cylinder pressures are seen for $30^{\circ}$ BTDC SOI. Advanced SOI results in more time available for formation of premixed charge. Therefore, relatively larger fraction of fuel is burnt in the premixed phase. Earlier SOI also leads to longer ignition delay due to relatively colder conditions (lower pressures and temperatures) prevailing in the combustion chamber at the time of start of fuel injection. Therefore higher fuel quantity is injected before the start of combustion (SOC). Once combustion starts, higher in-cylinder temperature is attained because of higher premixed heat release, which also leads to relatively higher peak in-cylinder pressure. The peak in-cylinder pressure largely depends upon the fuel fraction burnt during the premixed combustion phase.

Figure 3 shows variation in peak in-cylinder pressure and its crank angle position at various SOI timings for different loads. It can be seen from figure 3 that peak cylinder pressure is higher for advanced SOI timings compared to retarded ones. Peak in-cylinder pressure increased from 45.6 bar at no load to 46.9 bars at $3 \mathrm{~kW}$ load at $25^{\circ}$ BTDC SOI timing, whereas it increased from 51.3 bars at no load to 62.3 bars at $3 \mathrm{~kW}$ load at $40^{\circ}$ BTDC SOI timing. With increasing engine load, peak cylinder pressure increased and its position shifted away from TDC due to higher 

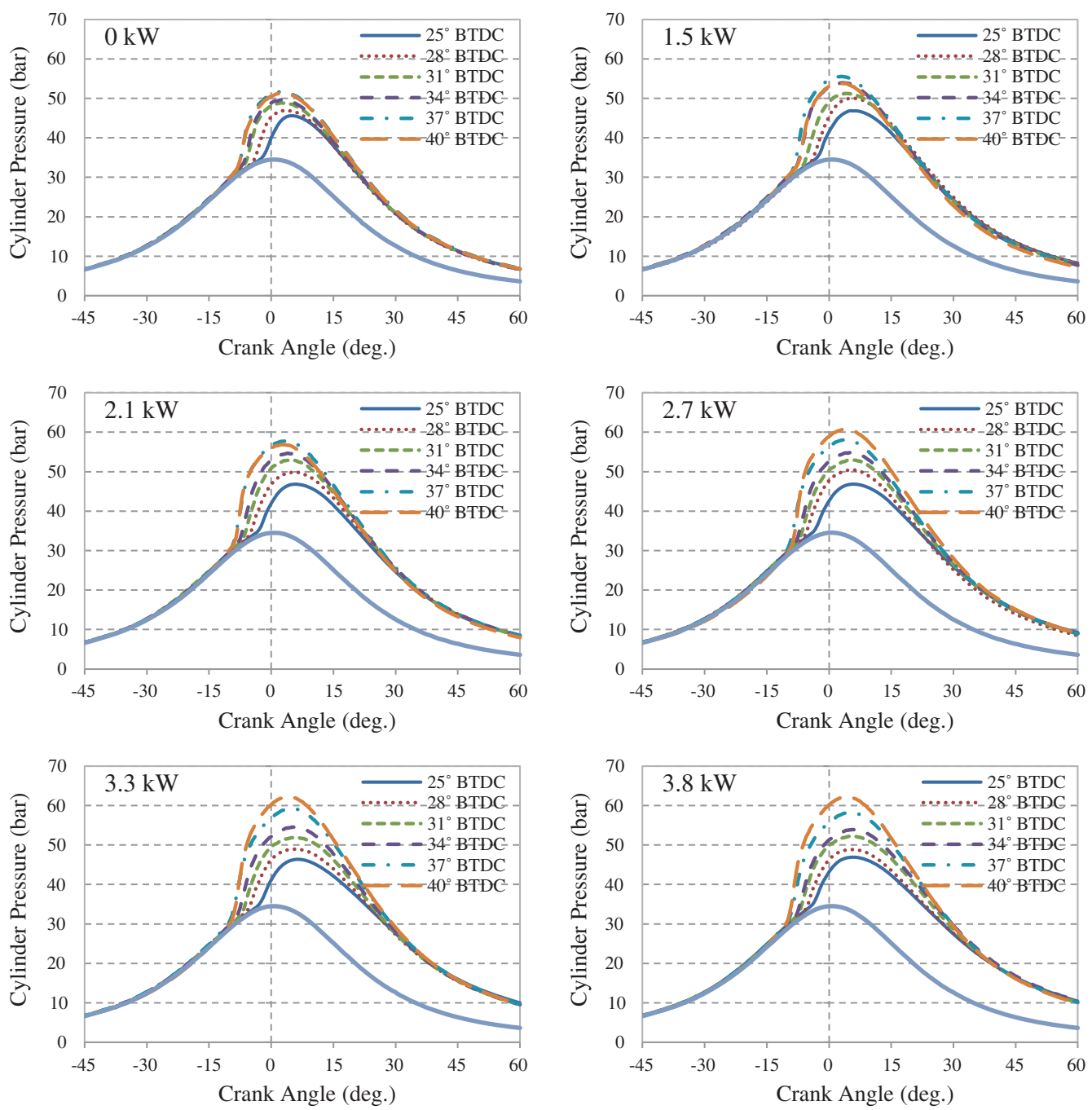

Figure 2. In-cylinder pressure vs. crank angle diagram for different SOI at varying engine loads.

fuel quantity being burnt, which results in longer combustion duration therefore the pressure peak appears relatively later in the expansion stroke.

3.1b Rate of pressure rise: The rate of pressure rise is a parameter, which gives information about the rate of force transfer due to in-cylinder combustion pressure exerted by burning and expanding gases onto the mechanical linkages of the engine and has a direct bearing on engine's structural safety. Figure 4 shows the rate of pressure rise for different SOI timings at various engine loads.

The rate of pressure rise reaches its maxima during premixed combustion phase due to rapid combustion and very fast premixed heat release (figure 4). After attaining the maxima, it reduces in the expansion stroke due to mixing controlled combustion, where the combustion is relatively 

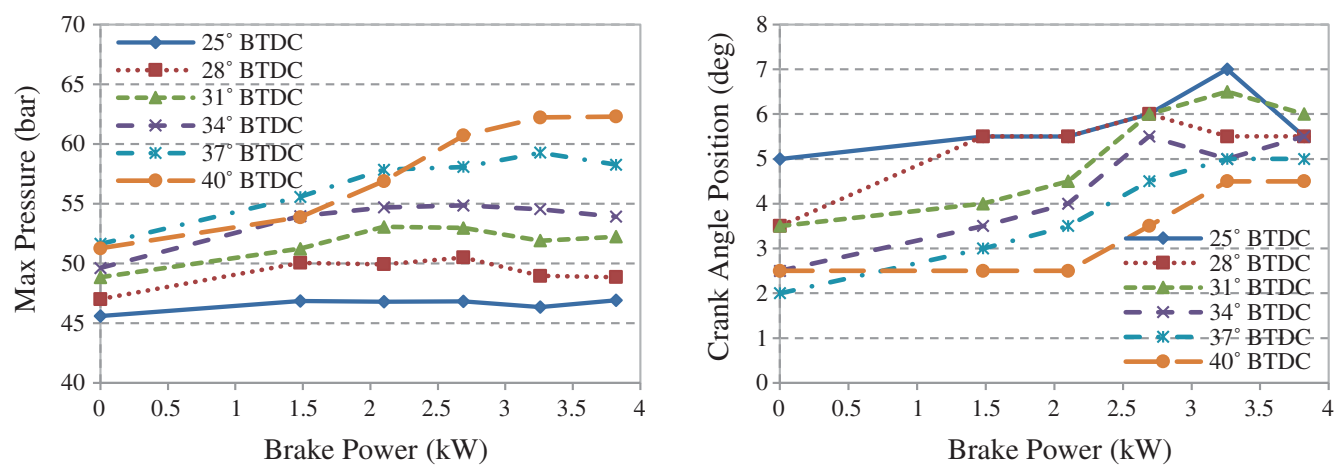

Figure 3. Peak in-cylinder pressure and its position for various SOI timings at different loads.

slower in addition to increase in combustion chamber volume due to movement of piston in expansion stroke. For advanced SOI timings, rate of pressure rise is much higher than that at retarded SOI timings. Due to longer ignition delay, larger fuel quantity is accumulated in the combustion chamber during this delay period. This leads to higher premixed charge available at the time of beginning of premixed combustion. Combustion of this premixed charge therefore yields relatively higher heat release rates and consequently higher pressure rise rates.

Figure 5 shows the variation in maximum rate of pressure rise and its crank angle position. As the engine load increases, relatively higher in-cylinder temperature is seen, which reduces the ignition delay. This leads to relative earlier ignition of premixed charge; hence, there will be lesser fuel accumulation in the combustion chamber due to shorter ignition delay, leading to reduction in pressure rise rate with increasing engine load. Peak of pressure rise rate shifts away from the TDC (into the compression stroke) because of relatively slower combustion and heat release in predominantly mixing controlled combustion phase at higher engine loads.

3.1c Heat release rate: Figure 6 shows the heat release rate at various SOI timings for different loads. The graph indicates two distinct stages of heat release. The first is immediately after the SOI to a point, where the heat release rate sharply drops. This is due to combustion primarily in the premixed combustion phase. The second phase starts from the end of first phase (Premixed combustion) to the end of combustion and this is called 'mixing-controlled combustion phase'. This is generally a slower heat release phase among the two, therefore, it spreads over a longer combustion duration and is essentially controlled by the rate, at which, the fuel and air can mix together inside the combustion chamber.

Heat release rate curve peak is seen to be higher for advanced SOI timings compared to the one with retarded SOI timings because relatively higher fraction of the fuel quantity injected burns in the premixed combustion phase for advanced SOI timings. This also explains the trends of in-cylinder pressure and pressure rise rate curves observed earlier.

Figure 7 shows the maximum heat release rate and the crank angle position, at which maximum heat release rate takes place. At higher engine loads, the fraction of heat release taking place in the mixing controlled combustion phase is higher because the ignition delay is shorter for higher engine load. Therefore smaller fuel quantity is available in combustion chamber at the time of premixed combustion, which lowers the peak and the crank angle position of this peak of heat release rate also shifts towards TDC. Combustion of diesel is mainly dominated by 

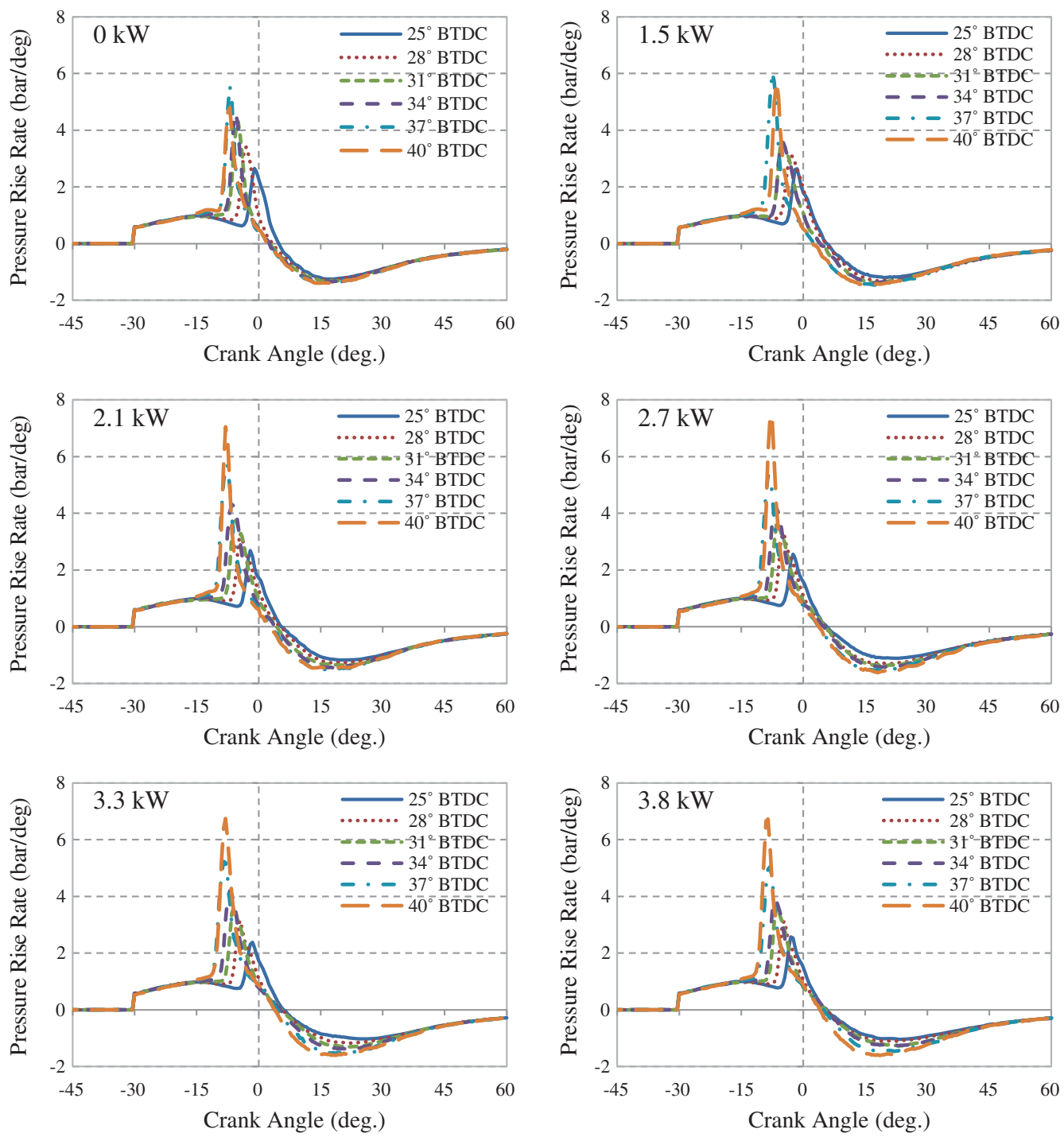

Figure 4. Pressure rise rate vs. Crank angle for various SOI timings at different loads.

mixing-controlled combustion at higher engine loads; however, the HRR is slower for this phase therefore it is not seen as a peak (Maxima) in these figures.

3.1d Mass burn fraction (MBF) and combustion duration: Mass burn fraction and other calculations are done based on standard assumptions made for thermodynamic analysis of diesel engine combustion. Figure 8 shows the crank angle position for 5 and $95 \%$ mass burn fractions (MBF) for various SOI timings at different loads. Advanced fuel injection timings show earlier combustion (fuel mass burn) compared to retarded SOI timings. Timing for 5\% MBF is generally regarded as 'start of combustion (SOC)' and 95\% MBF is generally regarded as 'end of combustion (EOC)' and the crank angle duration between these two MBFs is considered as 'combustion 

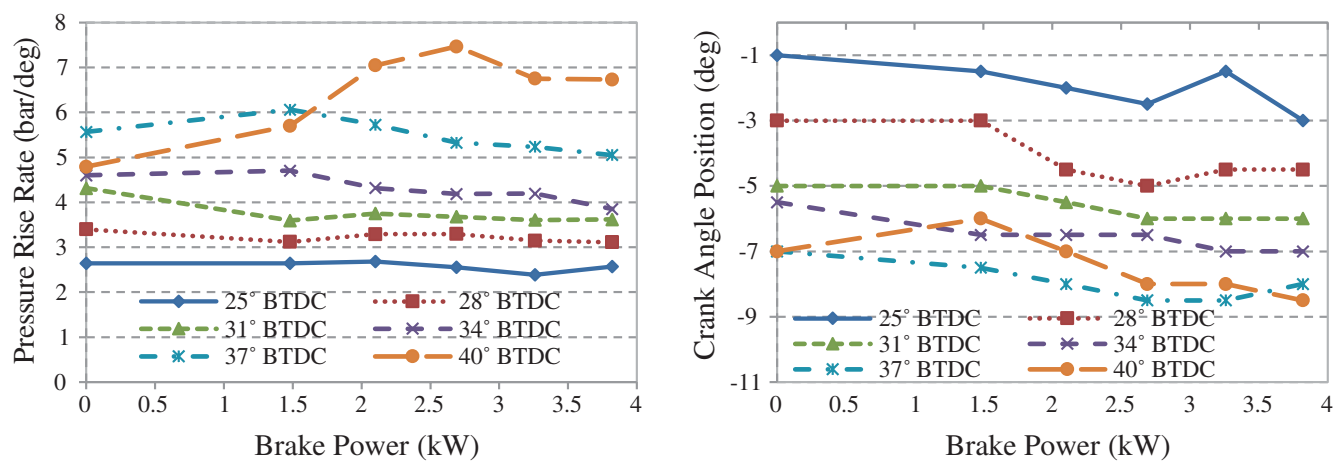

Figure 5. Maximum rate of pressure rise and its position for various SOI timings at different loads.

duration'. With increasing engine load, the crank angle position shifts away from TDC due to increase in fuel quantity injected, leading to longer combustion duration. One can also observe that with increasing engine load, $5 \% \mathrm{MBF}$ timing shifts earlier i.e. the combustion starts earlier during the compression stroke. This is indicated in previous sections also.

Combustion duration for different SOI timings is shown in figure 9. This figure indicates that the combustion duration increases with increasing engine load. This is primarily because of relatively higher fuel quantity injected with increasing engine load, which takes longer time to burn in premixed and mixing controlled phases put together.

Combustion duration is higher for advanced SOI timings, except $40^{\circ}$ BTDC SOI. However for higher engine load $(3.8 \mathrm{~kW})$, combustion duration is higher for retarded SOI timings due to combustion of higher fuel fraction taking place in the expansion stroke.

\subsection{Performance characteristics}

The engine performance of this newly developed CRDI system is evaluated by performing experiments and calculating parameters such as brake thermal efficiency (BTE) and exhaust gas temperature. The experiments are done three times at each load-speed combination and an average value is reported. Error bars represent accuracy of the reported data calculated from uncertainty values derived from accuracy of the instruments used in this investigation. BTE shows the fraction of thermal energy of fuel, which is converted into useful mechanical power by the engine at given engine operating conditions.

3.2a Brake thermal efficiency (BTE): Brake thermal efficiency of the engine is inversely proportional to the brake specific fuel consumption (BSFC), when a single fuel is being used, therefore BSFC is not calculated separately in this study. Figure 10 shows the trends for BTE v/s engine load for varying SOI timings at different engine loads.

BTE increased up to maxima (close to $3.5 \mathrm{~kW}$; figure 10) and then it started to decrease for all SOI timings. One can note from figure 10 that at $34^{\circ}$ BTDC SOI timing, highest BTE for all engine loads is observed. With retarded and advanced fuel injection timings than $34^{\circ} \mathrm{BTDC}$ SOI timing, BTE tends to decrease. Since maximum BTE is obtained at $34^{\circ}$ BTDC SOI, this is an optimum SOI timing for this newly developed single cylinder CRDI engine for all loads at $1,500 \mathrm{rpm}$. With retarded injection timings, there is significant fraction of fuel available for mixing controlled combustion as well as late combustion phase and the combustion extends 

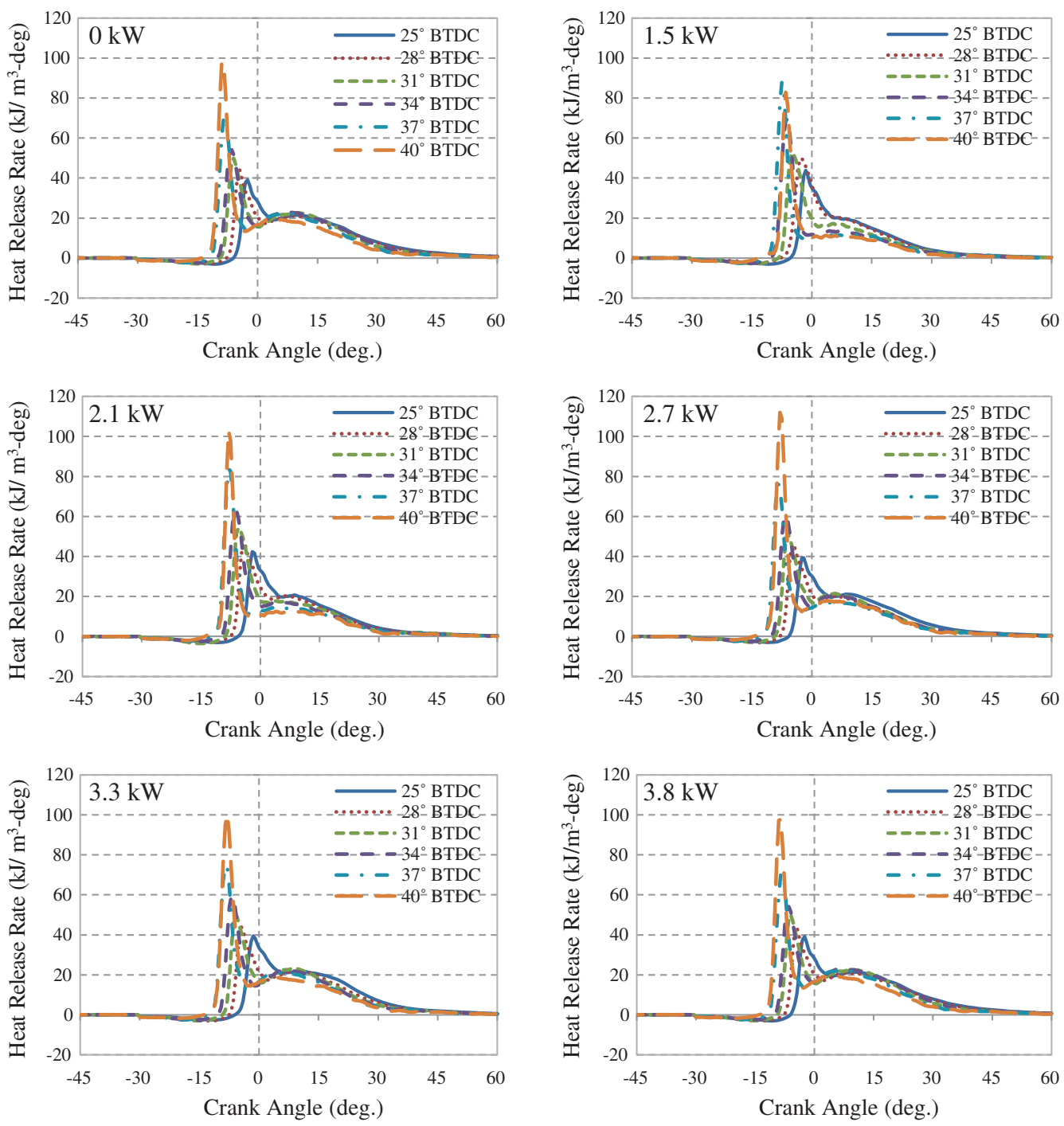

Figure 6. Heat release rate for various SOI timings at different loads.

well into the expansion stroke. This leads to effective reduction in the pressure force exerted by the combusting gases on the engine piston pushing it downward during the expansion stroke because of increased combustion chamber volume. Therefore this effectively reduced the BTE. With advanced SOI timings, combustion occurs relatively earlier, and the pressure exerted by combusting gases actually opposes the piston motion upwards (towards the TDC) during the compression stroke, which effectively leads to reduction in engine power output therefore it reduces the BTE.

3.2b Exhaust gas temperature: The exhaust gas temperature for different SOI timings for varying engine loads is shown in figure 11. 

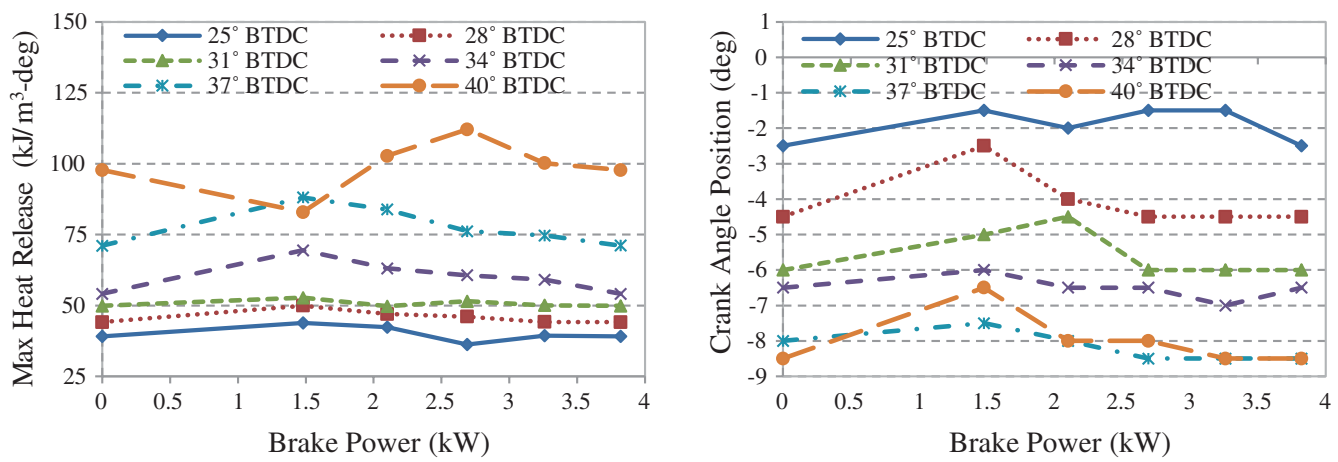

Figure 7. Maximum heat release rate and its crank angle position for various SOI timings at different loads.
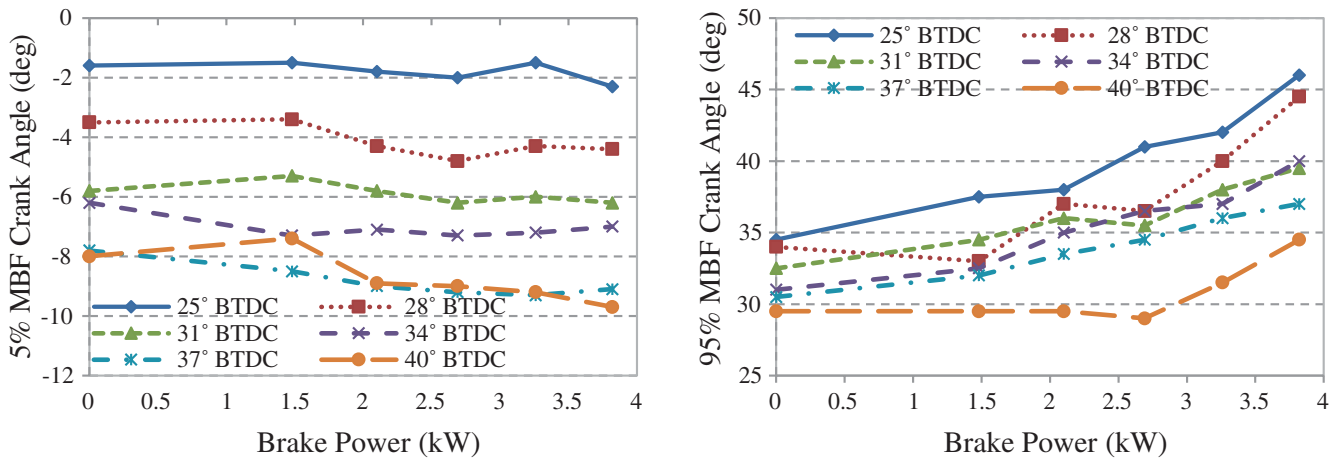

Figure 8. Five and 95\% MBF timings for various SOI timings at different loads.

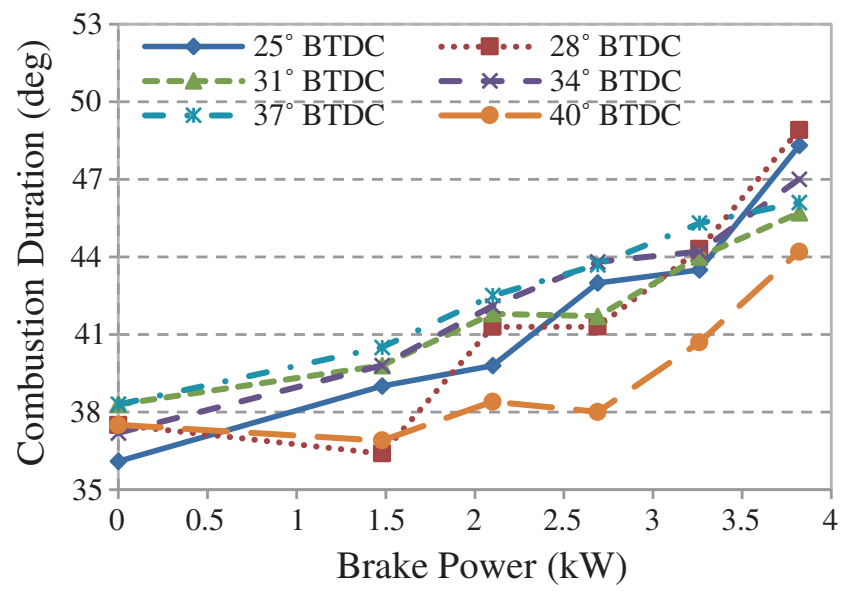

Figure 9. Combustion duration for various SOI timings at different loads.

Exhaust gas temperature increases with increasing engine load. This is because higher fuel quantity is injected at higher engine loads. Injection duration for higher fuel quantity is longer because the fuel is injected at constant pressure from the high pressure fuel rail. For longer 


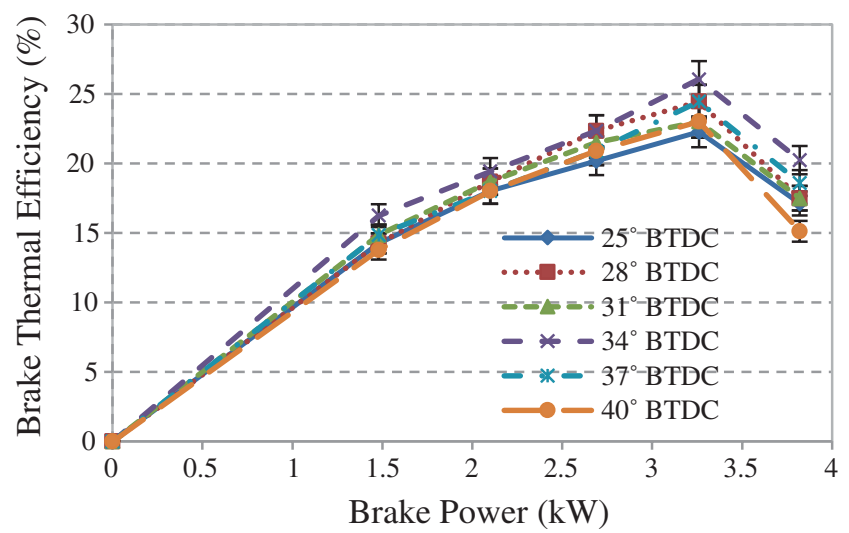

Figure 10. BTE of the engine for various SOI timings at different loads.

fuel injection duration, premixed combustion phase shortens and mixing controlled combustion phase elongates as seen earlier, and large amount of heat is released in mixing controlled and late combustion phases. It can be seen from figure 11 that by retarding the SOI timings, major part of combustion takes place in mixing controlled combustion phase therefore the combustion duration becomes longer, leading to the higher temperatures of the exhaust gases at the engine exhaust gas outlet.

\subsection{Emissions characteristics}

Emissions characteristics of the newly developed CRDI FIE system can be assessed by measuring the raw emissions of oxides of nitrogen $\left(\mathrm{NO}_{\mathrm{x}}\right)$, unburnt hydrocarbons $(\mathrm{HC})$, carbon monoxide $(\mathrm{CO})$ and Smoke opacity and reporting them as mass emissions.

3.3a BSNO $\mathrm{B}_{x}$ emissions: The formation of $\mathrm{NO}_{\mathrm{x}}$ in $\mathrm{CI}$ engines is largely dependent on the overall oxygen concentration in the combustible mixture, peak cylinder temperatures, and the residence time of the combusting mixture at the peak cylinder temperature. The variation in mass

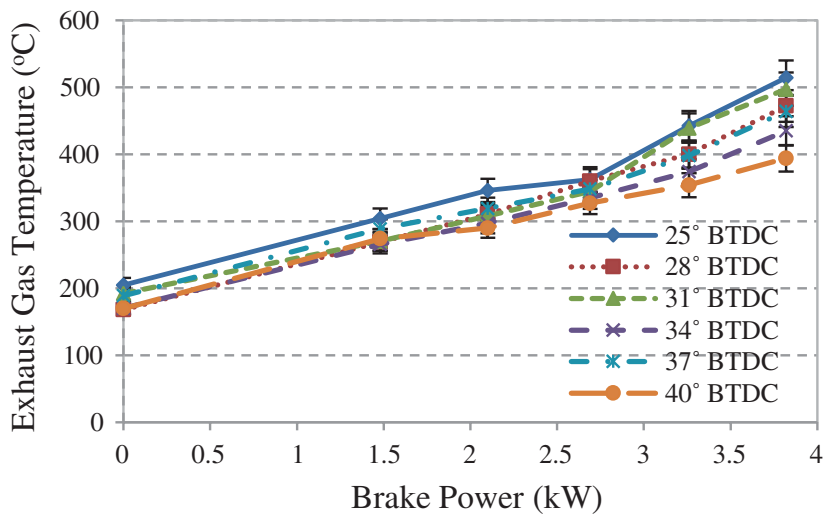

Figure 11. Exhaust gas temperature for various SOI timings at different loads. 
emission of $\mathrm{NO}_{\mathrm{x}}$ for different SOI timings in this newly developed CRDI engine is shown in figure 12. The results showed that there is overall reduction in the mass emission of $\mathrm{NO}_{\mathrm{x}}$ with increasing engine loads. There are several factors responsible for reduction in mass emission of $\mathrm{NO}_{\mathrm{x}}$ with increasing engine load namely: (i) reduction in oxygen concentration in the combustible mixture because of higher fuel quantity being injected; (ii) increase in turbulence level at higher engine loads, resulting in lower residence time for $\mathrm{NO}_{\mathrm{x}}$ specific reactions; and (iii) relatively lower combustion temperatures for richer fuel-air mixtures because of longer combustion durations and heat release rates. Advanced SOI timings result in relatively higher $\mathrm{BSNO}_{\mathrm{x}}$ emissions due to higher heat release rate in premixed combustion phase, which leads to very high peak combustion pressures and temperatures.

3.3b BSHC emissions: HC emissions from the engine are mainly because of incomplete combustion of fuel in the combustion chamber and partial combustion of lubricating oil being thrown into the combustion chamber because of piston and ring dynamics. Richer as well as leaner fuel-air mixtures, both lead to hydrocarbon emissions, due to lesser availability of oxygen in the combustion zone and misfires respectively. Variations in BSHC emissions at different SOI timings for varying engine loads are shown in figure 13. At lower engine loads, BSHC emissions are relatively higher for all SOI timings due to lower engine output power (which is a denominator, while calculating the brake specific mass emissions). With increasing engine load, BSHC emissions wither remain constant or decrease. They start increasing again, at further higher engine loads. At higher engine loads, more fuel quantity is injected into the combustion chamber with a constant mass of intake air (because of constant engine speed). As a result, the fuel-air mixture becomes richer in various zones in the combustion chamber with increasing engine load, leading to higher HC emissions. Figure 13 also suggests that with retarded SOI timings, mass emission of $\mathrm{HC}$ is higher in comparison to advanced SOI timings. This happens due to delayed SOC and relatively slower heat release rates for the combustible charge at retarded SOI timings. Inconsistent $\mathrm{HC}$ emissions for $37^{\circ} \mathrm{SOI}$ timings are observed in figure 13 because of beginning of knocking combustion in these conditions.

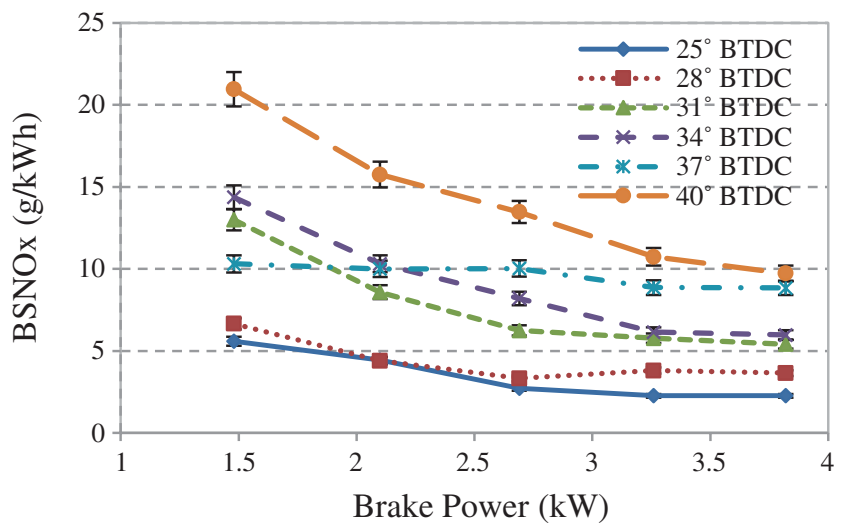

Figure 12. $\mathrm{BSNO}_{\mathrm{x}}$ emissions for various $\mathrm{SOI}$ timings at different loads. 


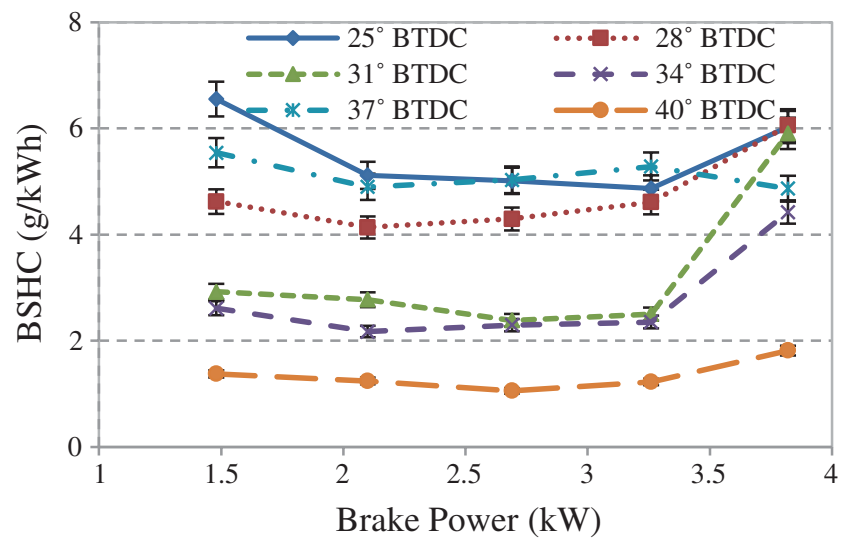

Figure 13. BSHC emissions for various SOI timings at different loads.

3.3c BSCO emissions: $\mathrm{CO}$ is an intermediate combustion product formed due to incomplete combustion of hydrocarbon fuels. $\mathrm{CO}$ emissions are largely affected by the stoichiometry. Mass emissions of $\mathrm{CO}$ at varying engine loads for different SOI timings are shown in figure 14. Figure 14 shows that at lower engine loads, BSCO emissions were lower. BSCO emissions increase with increasing engine loads sharply towards the higher loads. As engine load increases, relative fuel-air ratio also increases, resulting in richer heterogeneous combustion, which leads to inefficient mixing of fuel and air, resulting in higher $\mathrm{CO}$ emissions under high engine load conditions. There is no significant effect of SOI timings on BSCO emissions in this newly developed CRDI system.

3.3d Smoke opacity: The variation of smoke opacity for different engine operating conditions for all SOI timings is shown in figure 15. There is an overall increase in smoke opacity with increasing engine load, which indicates that the exhaust stream is having higher particulate emissions. Increasing engine load results in an increase in fuel-air equivalence ratio and longer mixing controlled combustion phase, which results in higher combustion temperatures as well

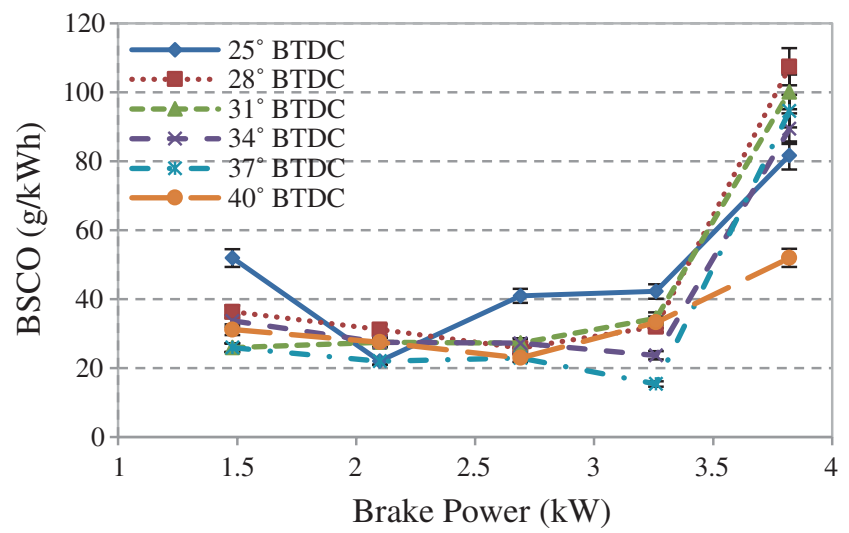

Figure 14. BSCO emissions for various SOI timings at different loads. 


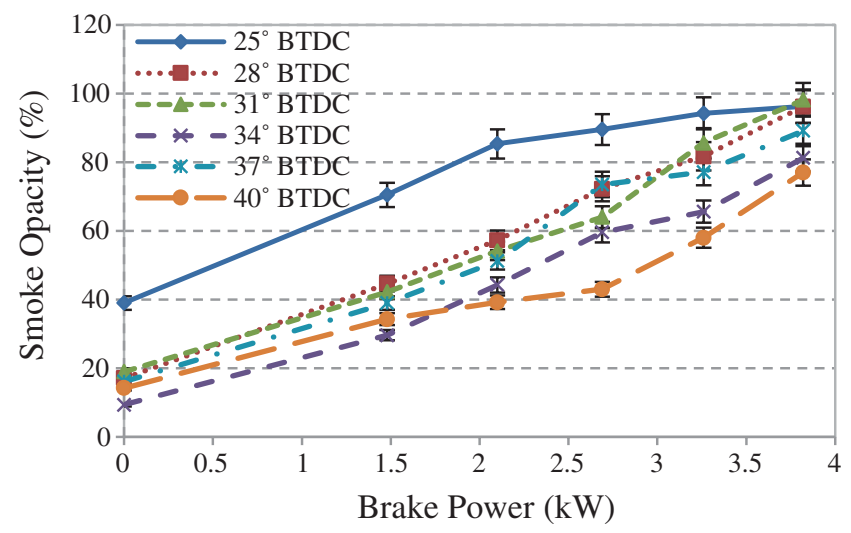

Figure 15. Smoke opacity for various SOI timings at different loads.

as lower oxygen concentration in the engine combustion chamber, therefore the smoke opacity increases. It is evident from the figure that SOI timings play a vital role in smoke opacity i.e. soot formation. Retarded SOI timings increase smoke opacity due to lower in-cylinder combustion temperatures and reduction in the time available for oxidation and re-burning of soot already formed during expansion stroke. Advanced SOI timings lead to more complete combustion at relatively elevated in-cylinder temperatures, resulting in lower soot opacity. These trends are exactly opposite to the ones observed for $\mathrm{BSNO}_{\mathrm{x}}$ emissions.

\section{Conclusions}

In this study, a simple and cheaper version of CRDI FIE system for single cylinder, constant speed engines was successfully developed. The ECU and large number of sensors of conventional CRDI system were replaced by simpler electronic circuits and basic sensors in order to control the cost of the system. Effect of SOI timings on this new engine's performance, emissions and combustion characteristics was experimentally investigated. Advanced SOI timings showed higher in-cylinder pressures, higher pressure rise rates and higher heat release rates, primarily due to relatively longer ignition delays. As the engine load increases, relative contribution of premixed combustion phase to the total heat release decreases due to reduction in ignition delay and mixing controlled combustion phase starts to dominate the engine combustion and total heat release process. Maximum heat release rate and peak cylinder pressure shifts away from TDC. For retarded SOI timings, due to the late combustion, peak pressure occurs later in the expansion stroke of this CRDI engine. $34^{\circ}$ BTDC SOI gives best thermal efficiency. Any variation in SOI timings in either direction leads to a fuel penalty. The exhaust gas temperatures were found to increase at retarded SOI timings. For advanced SOI conditions, lower BSHC and higher $\mathrm{BSNO}_{\mathrm{x}}$ emissions were observed. There is no significant effect of SOI timings on BSCO emissions. Smoke opacity increases with retarded fuel injection due to reduction in combustion chamber temperatures. Overall, a simpler CRDI system for single cylinder engines with simpler control strategies is effective in getting the desired emissions and fuel economy benefits for cheaper engine application niche markets. 


\section{Acknowledgements}

Financial support from CSIR through their grant Sanction Letter No. 37(1505)/11/EMR-II dated 22 December 2011 for conducting this investigation is gratefully acknowledged and appreciated.

\section{References}

Block B, Westphal H, Oppermann W, Hentschel W, Henning H and Kutschera I 2002 Optical detection of the combustion produced by the pre-injected fuel in a DI diesel engine, SAE Paper 2002-01-2667

Cheng W T, Sub H J, Xie X, Chia L M, Henein N A, Schwarz E and Bryzik W 1999 Direct visualization of high pressure diesel spray and engine combustion, SAE Paper 1999-01-3496

Desantes J M, Arregle J, Lopez J J and Garcia A 2007 A comprehensive study of diesel combustion and emissions with post-injection, SAE Paper 2007-01-0915

Eblen E and Stumpp G 1978 Beitrag des Einspritz systems zur Verbesserung des Diesel motors, Bosch Techn. Berichte Band 6, Heft 2

Endres H, Dumholz M and Frisse P 1994 Pre-injection: A measure to optimize the emission behavior of DI-diesel engines, SAE Paper 940674

Henein N A, Lai M C, Singh I, Wang D and Liu L 2001 Emissions trade off and combustion characteristics of a high speed direct injection diesel engine, SAE Paper 2001-01-0197

Ishiwata H, Ohishi T, Ryuzaki K, Unoki K and Kitahara N 1994 A feasibility study of pilot injection in TICS, SAE Paper 940195

Kohketsu S, Mori K, Kato T and Sakai K 1994 Technology for low emission, combustion noise and fuel consumption on diesel engine, SAE Paper 940672

Kong S C and Karra P K 2008 Diesel emission characteristics using high injection pressure with converging nozzles in a medium-duty engine, SAE Paper 2008-01-1085

Koyanagi K, Oing H, Renner G and Maly R 1999 Optimizing common rail-injection by optical diagnostics in a transparent production type diesel engine, SAE Paper 1999-01-3646

Miyaki M, Fujisawa H, Masuda A and Yamamota Y 1991 Development of new electronically controlled fuel injection system ECD-U2 for diesel engines, SAE Paper 910251

Nakakita K, Kondoh T, Ohsawa K, Takahashi T and Watanabe S 1992 Optimization of pilot injection pattern and its effect on diesel combustion with high-pressure injection. JSME Int. J. Series B - Fluids Thermal Eng. 37: 966-973

Riaud J C and Lavoisier F 2002 Optimizing the multiple injection settings on an HSDI diesel engine. In: THIESEL conference on Thermo and Fluid Dynamic Processes in Diesel Engines

Rinolf R, Imarisio R and Buratti R 1995 The potential of a new common rail diesel fuel injection system for the next generation of DI diesel engines, 16 Internationales Wiener Motoren symposium, VDI- Verlag Reihe 12 Nr. 239

Robert Bosch 2006 GmbH, Diesel-engine management. John Wiley and Sons Inc., UK, 72 Pages

Schubiger R, Bertola A and Boulouchos K 2001 Influence of EGR on combustion and exhaust emissions of heavy duty DI-diesel engines equipped with common-rail injection systems, SAE Paper 2001-01-3497

Shimada T, Shoji T and Takeda Y 1989 The effect of fuel injection pressure on diesel engine performance, SAE Paper 891919

Shundoh S, Komori M, Tsujimura K and Kobayashi S 1992 NOx reduction from diesel combustion using pilot injection with high pressure fuel injection, SAE Paper 920461

Thirouard M, Pacaud P, Ambrazas D, Chmielarczyk V, Mendez S, Garsi C, Lavoisier F and Barbeau 2009 Potential to improve specific power using very high injection pressure in HSDI Diesel engines, SAE Paper 2009-01-1524

Tow T, Pierpont D A and Reitz R D 1994 Reducing particulates and NOx emissions by using multiple injections in a heavy duty DI diesel engine, SAE Paper 940897 
Tsurushima T, Zhang L and Ishi Y 1999 A study of unburnt hydrocarbon emissions in small di diesel engine, SAE Paper 1999-01-0512

Uchida N, Shimokawa K, Kudo Y and Smimoda M 1998 Combustion optimization by means of common rail injection system for heavy duty diesel engines, SAE Paper 982679

Zhang L 1999 A study of pilot injection in a DI diesel engine, SAE Paper 1999-01-3493 